\title{
Calculation and Optimizing of Brake Thermal Efficiency of Diesel Engines Based on Theoretical Diesel Cycle Parameters
}

\author{
Safak Yildizhan $^{*}$, Vedat Karaman ${ }^{* *}{ }^{*}$, Mustafa Ozcanli $^{*}$, Hasan Serin ${ }^{*}$ \\ *Department of Automotive Engineering, Cukurova University, 01330 Adana, Turkey. \\ **Department of Mechanical Engineering, Istanbul Gelisim University, 34315 Istanbul, Turkey. \\ (yildizhans@cu.edu.tr, vkaraman@gelisim.edu.tr, ozcanli@cu.edu.tr, hserin@cu.edu.tr)
}

\begin{abstract}
† Corresponding Author: Vedat Karaman, Department of Mechanical Engineering, Istanbul Gelisim University, 34315
Istanbul, Turkey, Tel:+90 212 422700, Fax: +90 2124227401, vkaraman@ gelisim.edu.tr
\end{abstract}

Received: 25.07.2016 Accepted: 02.09.2016

\begin{abstract}
In this study, a theoretical study has been evaluated in order to calculate and optimize diesel engine brake thermal efficiency values. In the study three main parameters which are compression ratio, ratio of specific heat and cut-off ratio, based on ideal diesel cycle were evaluated. Compression ratio, ratio of specific heats and cut-off ratios were chosen between the interval of; 12:1-24:1, 1,2-1,4 and 1,5-3,0, respectively. Theoretical study showed that compression ratio significantly affects the engine characteristics that calculated in this study. Experiments revealed that the higher compression ratio results with higher brake thermal efficiency (BTHE) and thus lower specific fuel consumption (SFC). The calculation study showed that increasing cut-off ratio caused to decrease of brake thermal efficiency. Also, study revealed that increment of ratio of specific heats improved brake thermal efficiency.
\end{abstract}

Keywords Thermal efficiency, performance, compression ratio, specific heats, cut-off ratio, optimization.

\section{Introduction}

A large part of the energy consumed in the world is derived from fossil fuels such as petroleum, coal and natural gas. But, these petroleum based non-renewable resources will come to an end in the short run. Therefore, the investigations for renewable and sustainable alternative energy sources which can provide the necessary energy demand of the world has gained attention all over the world due to hazard of depletion of fuels, high price of petroleum and environmental concerns such as air pollution and global warming [1]. In the last decades, research interests on the internal combustion engines (ICE) have been explored in the area of alternate fuels, which are renewable, locally available, environment friendly [2]. Beside these fuel researches the operating conditions of engines have gained very importance by researchers and manufacturers. Improvement internal combustion engines by optimizing the all operating conditions have been one of the primary study subjects through researchers. To be able to increase the efficiency of an engine all effects of engine parameters should be known. Thus, many researchers have investigated the effects of these parameters mostly using variable compression engine (VCR) [2-8].

The diesel engines are very fuel efficient and thus provide fuel economy. The operational simplicity of diesel engines makes diesel engines more preferable in the transportation sector and agricultural and forestry machinery. The extinction risk of fossil fuel and high cost of the petroleum causes to increase of effort in the means of alternative fuel development. [9].

After the oil crisis of the 1970s, investigation efforts on the field of the internal combustion engines have been extended in the area of alternative fuels, which are available locally, biodegradable, less toxic, environment friendly renewable, compared to fossil fuels [10]. Also, beside fuel researches many scientists have been working on engine parameters such as compression ratio and injection timing. These main parameters of engines effect directly performance and emission characteristics of ICE. Thus, many researchers have investigated the effects of these parameters mostly using variable compression engine (VCR). 
Jindal et al. [3] reported a study which investigates the effects of the engine design parameters such as compression ratio $(\mathrm{CR})$ and fuel injection pressure on the performance of the engine. The author studied the subject with some critical performance criterias such as brake thermal efficiency, specific fuel consumption, and emissions of carbon monoxide, carbon dioxide, hydrocarbons, nitrogen oxides and smoke opacity with Jatropha methyl ester as fuel. Depnath et al. [11] presented a study that investigates the variable compression ratio diesel engine when the engine is fueled with palm oil methyl ester thermodynamically. The effect of compression ratio (CR) and injection timing (IT) on energy and energy potential of a palm oil methly ester (POME) was found by them. The test were performed in a single cylinder, direct injection, water cooled variable compression ratio diesel engine at a constant peed of 1500 rpm under a full load. Amarnath and Prabhakaran [10] reported a study which is related with the thermal performance and emissions of a variable compression ratio diesel engine fueled with karanja biodiesel and optimized the parameters based on experimental datas. Al Dawody and Bhatti[12] investigated the emission, performance and the combustion, characteristics of a diesel engine fueled with soybean biodiesel-diesel blends experimentally and computationally.

In this study, a theoretical calculation were evaluated based on ideal diesel cycle by using parameters of compression ratio, ratio of specific heats, and cut-off ratio in order to optimize the operational conditions of a diesel engine. Theoretical calculations in this study shows the effects of engine operating parameters which is important to have guess before performing time consuming and costly experiments.

\section{Material Method}

\subsection{Calculation Method}

The most crucial characteristic of diesel engine is its fuel economy, which can excel up to $40 \%$ in vehicle applications and even up to $50 \%$ in two-stroke units of marine exciting or generators. As a consequence, vehicles running with compression ignition engines have lower specific fuel consumption and reduced carbon dioxide emissions comparing to its counterpart spark ignition engines. Moreover, diesel engines are less sensitive in terms of airfuel ratio variations, in peak cylinder pressures and temperatures absence of throttling, high torque and high tolerability make diesel engines more preferred.

Compression ignition engines are assumed to operate with the principle of ideal cycle. Actual working cycle of diesel cycle is significantly different from ideal cycles. Yet, to be able to study parametrically actual cycles are idealized with some assumptions.

\section{Ideal Diesel Cycle}

In compression-ignition engines, air is compressed to above the auto ignition temperature of the fuel. After the injection of fuel spray the combustion occurs with a delay time (ignition delay, a few crack angles). Diesel (compression ignition) engines are mostly used for heavy-duty vehicles, trucks, buses, etc. which require a very high amount of torque.

Intake stroke: The piston starts to move downward from the top dead center to bottom dead center, the intake valve opens, and this movement lets the introducing the air charge inside the cylinder.

Compression stroke: The piston moves back to top dead center from bottom dead center and compresses the air inside the cylinder and the temperature inside cylinder rises over the auto-ignition temperature of the fuel.

> Combustion stroke (power stroke) : At the end of the compression stroke (before the piston reaches the top dead center) the injectors start to inject fuel inside to cylinder. After the ignition delay period the fuel is spontaneously auto-ignites. The fuel-air mixture combust produce a pressure on the cylinder head and pushes the cylinder downward which is the main object of the engine.

$>$ Exhaust stroke: After the piston hits the bottom of cylinder (bottom dead center) ,the piston start to move upward and the exhaust valve opens because between the cylinder and exhaust manifold pressure is different, and the sweep effect of the piston make the exhaust gases leave the cylinder to go out through the tail pipe.

The four steps of ideal diesel combustion ;

1-2 isentropic compression

2-3 constant pressure heat addition

3-4 isentropic expansion

4-1 constant volume heat rejection

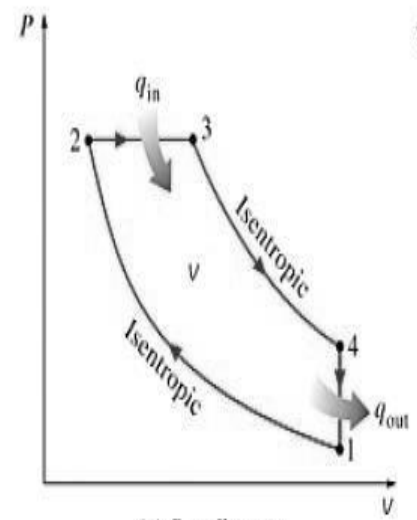

(a) P-v diagram

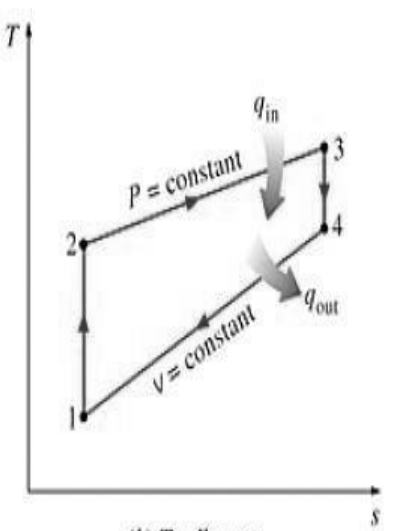

(b) T-s diagram
Fig 1.a.b P-V and T-S diagrams of idealized diesel cycle

Underlining that the ideal diesel cycle is operated in a closed system, and air-standard assumptions were made for working fluid (air). Variations of potential and kinetic energies are insignificant. During the two isentropic processes no heat transfer is involved. The energy balances processes are:

$-\mathrm{w}_{12}=\mathrm{u}_{2}-\mathrm{u}_{1}$

$-\mathrm{w}_{34}=\mathrm{u}_{4}-\mathrm{u}_{3}$ 
$\mathrm{W}_{12}$ is negative because of the compression and $\mathrm{W}_{34}$ is positive because of the expansion process which air does the work. Constant pressure heat addition process,

$\mathrm{w}_{23}=\mathrm{P}_{2}\left(\mathrm{v}_{3}-\mathrm{v}_{2}\right)$

The energy balances:

$\mathrm{q}_{23}=\mathrm{u}_{3}-\mathrm{u}_{2}+\mathrm{w}_{23}=\mathrm{h}_{3}-\mathrm{h}_{2}$

Since there is no change in the volume there is no work in the heat rejection process. The energy balance;

$\mathrm{q}_{41}=\mathrm{u}_{1}-\mathrm{u}_{4}$

Since the heat is added to the system $\mathrm{q}_{23}$ is positive and since the heat is rejected during the process $\mathrm{q}_{41}$ is negative.

For the full cycle,

$\mathrm{q}_{23}+\mathrm{q}_{41}-\mathrm{w}_{12}-\mathrm{w}_{34}=0$

Brake thermal efficiency $\left(\eta_{\text {th }}\right)$ : A gauge of overall engine efficiency is given by the brake thermal efficiency. Brake thermal efficiency is the ratio of energy in the brake power to the fuel energy. Figure A shows the entropy (S), pressure (P) and volume (V) diagrams of idealized diesel cycle.

Thermodynamically;

$$
\begin{aligned}
& \mathrm{W}_{\text {cycle }}=\oint P d V=\oint T d s \\
& \mathrm{Q}_{2-3}=\int_{T_{2}}^{T_{3}} c_{\mathrm{p}} d T \quad \mathrm{Q}_{4-1}=-\int_{T_{4}}^{T_{1}} c_{\mathrm{v}} d T \\
& \mathrm{Q}_{2-3}=\mathrm{c}_{\mathrm{p}}\left(\mathrm{T}_{3}-\mathrm{T}_{2}\right) \quad \mathrm{Q}_{4-1}=-\mathrm{c}_{\mathrm{v}}\left(\mathrm{T}_{1}-\mathrm{T}_{4}\right)=\mathrm{c}_{\mathrm{v}}\left(\mathrm{T}_{4}-\mathrm{T}_{1}\right) \\
& \eta_{\mathrm{th}}=\frac{Q_{2-3}-Q_{4-1}}{Q_{2-3}} \eta_{t h}=1-\frac{Q_{4-1}}{Q_{2-3}} \gamma=\frac{c_{p}}{c_{v}} \\
& \eta_{t h}=1-\frac{c_{v}\left(T_{4}-T_{1}\right)}{c_{p}\left(T_{3}-T_{2}\right)} \quad \eta_{t h}=1-\frac{\left(T_{4}-T_{1}\right)}{\mathrm{Y}\left(T_{3}-T_{2}\right)} \\
& \alpha=\frac{V_{3}}{V_{2}}
\end{aligned}
$$

Since 1-2 adiabatic

$$
T_{2}=T_{1} r^{\Upsilon^{-1}}
$$

Since 2-3 constant pressure

$$
\begin{aligned}
& P_{2} V_{2}=m R T_{2} \quad P_{a} V_{a}=m R T_{a} T_{a}=T_{2} \frac{V_{3}}{V_{2}} \\
& T_{a}=T_{2} \alpha \quad T_{a}=T_{1} \alpha r^{\Upsilon^{-1}} \\
& P_{4} V_{4}^{\mathrm{Y}}=P_{\mathrm{a}} V_{\mathrm{a}}^{\mathrm{Y}} \quad P_{4} V_{4} V_{4}^{\mathrm{Y}-1}=P_{\mathrm{a}} V_{\mathrm{a}} V_{\mathrm{a}}^{\mathrm{Y}-1} \\
& P_{4} V_{4}=m R T_{4} \quad P_{a} V_{a}=m R T_{a} \\
& \frac{T_{4}}{T_{3}}=\left(\frac{v_{3}}{v_{4}}\right)^{T^{-1}} \\
& \frac{T_{4}}{T_{a}}=\left(\frac{V_{a}}{V_{4}}\right)^{\mathrm{\gamma}-1}=\left(\frac{V_{a}}{V_{2}}\right)^{\mathrm{T}-1}\left(\frac{V_{2}}{V_{4}}\right)^{\mathrm{T}-1}
\end{aligned}
$$

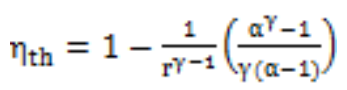

$$
\begin{aligned}
& \left(\eta_{\text {th }}\right)=\text { BrakePower/Fuel Energy }
\end{aligned}
$$

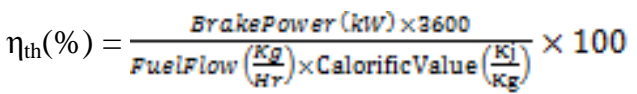

Where;

$\eta_{t h}$ is thermal efficiency,

$\alpha$ is the cut-off ratio (ratio between the end and start volume for the combustion phase),

$\mathrm{c}_{\mathrm{p}}$ is specific heat at constant pressure,

$\mathrm{c}_{\mathrm{v}}$ is specific heat at constant volume,

$\gamma$ is ratio of specific heats $\left(c_{\mathrm{p}} / \mathrm{c}_{\mathrm{v}}\right)$,

$\mathrm{r}$ is the compression ratio.

Theoretical equation shows that thermal efficiency of the diesel cycle depends on three parameter which are; compression ratio $(r)$, ratio of specific heats $(\gamma)$ and cut-off ratio of the cycle $(\alpha)$.

\section{Results and Discussion}

In this study, a theoretical calculation of brake thermal efficiency (BTHE) was evaluated analytically. Three main parameters that effect the thermal efficiency calculation of ideal diesel cycle were studied. Compression ratio which is the main parameter that determines the theoretical BTHE value was varied between the range of $12: 1$ and 24:1. Ratio of specific heats $(\gamma)$ and cut-off ratios $(\alpha)$ were chosen between the rage of 1,2-1,4 and 1,5-3,00, respectively.

Figures (1-5) shows the BTHE values of for different compression ratios, cut-off ratios and specific heat ratios. The analyses revealed that, CR increment significantly increases BTHE values. For all cut-off ratios and specific heat ratios maximum BTHE values were obtained with 24:1 compression ratio value. Increasing specific heats $(\gamma)$ values further increased BTHE values. But, increasing cut-off ratio $(\alpha)$ values caused a significant decrement in the means of BTHE values. According to calculation results, the best efficiency of thermal study was obtained with 1,4 specific heat ratio, 1,5 cut-off ratio and 24:1 CR.

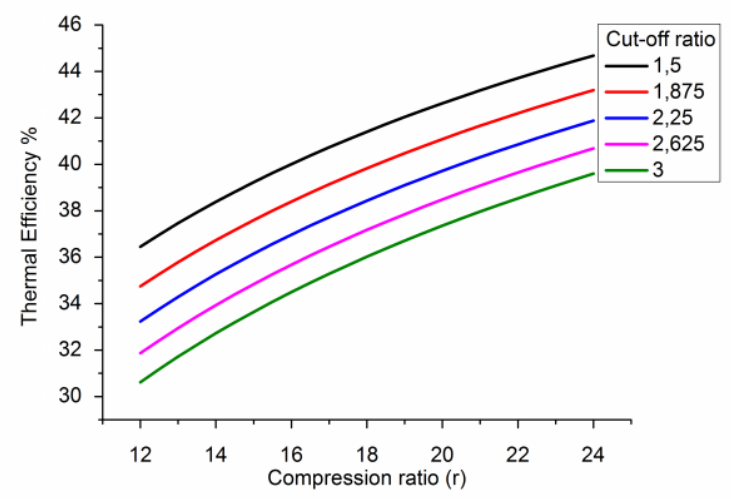

Fig. 1. The change in thermal efficiency according to different compression and cut off ratio in cases where ratio of specific heats $(\gamma)$ is 1.2 constant 


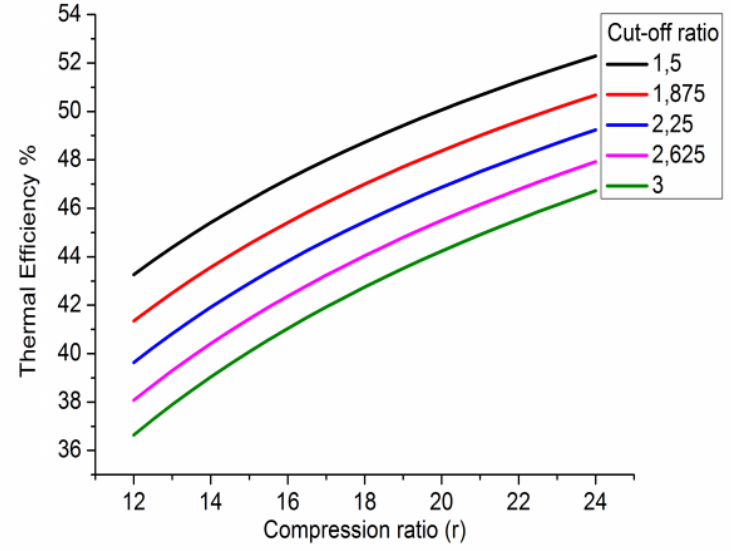

Fig. 2. The change in thermal efficiency according to different compression and cut off ratio in cases where ratio of specific heats $(\gamma)$ is 1.25 constant

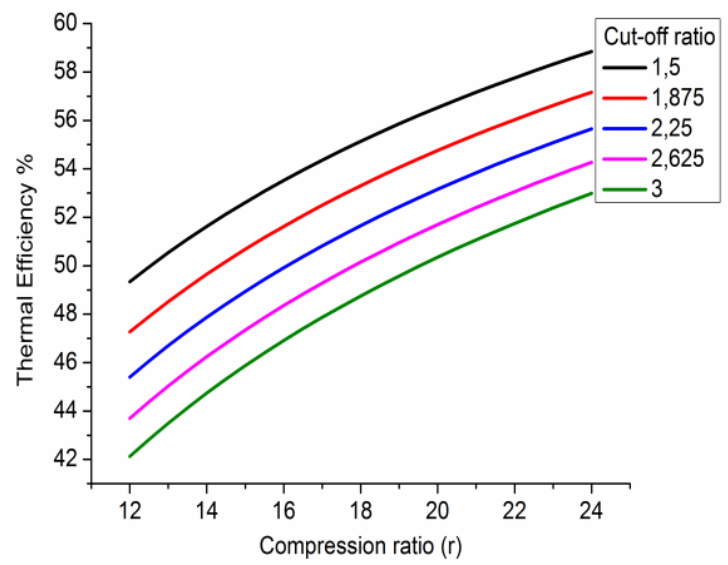

Fig. 3. The change in thermal efficiency according to different compression and cut off ratio in cases where ratio of specific heats $(\gamma)$ is 1.3 constant

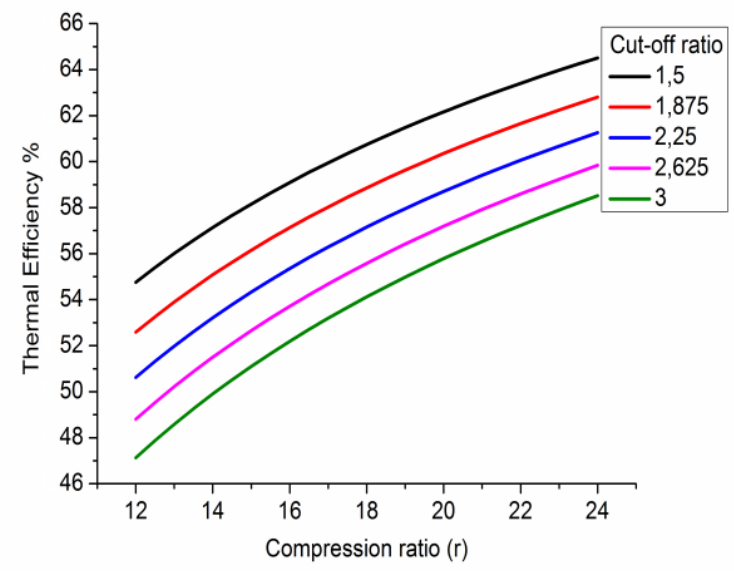

Fig. 4. The change in thermal efficiency according to different compression and cut off ratio in cases where ratio of specific heats $(\gamma)$ is 1.35 constant

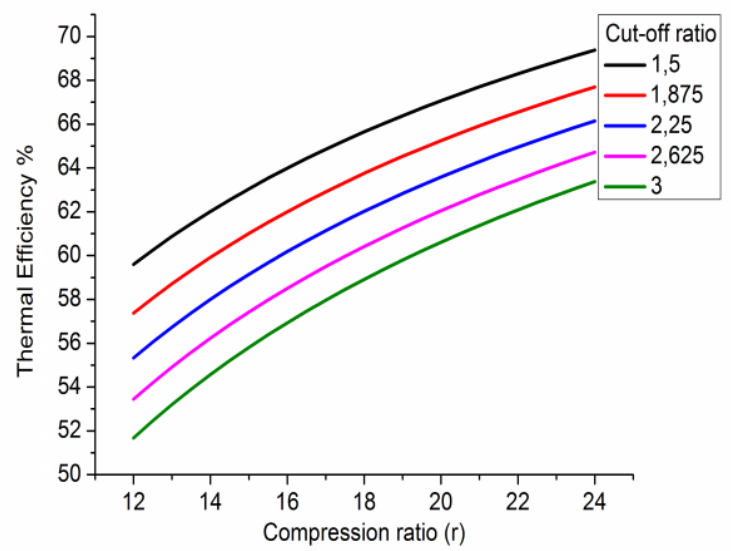

Fig. 5. The change in thermal efficiency according to different compression and cut off ratio in cases where ratio of specific heat $(\gamma)$ is 1.4 constant

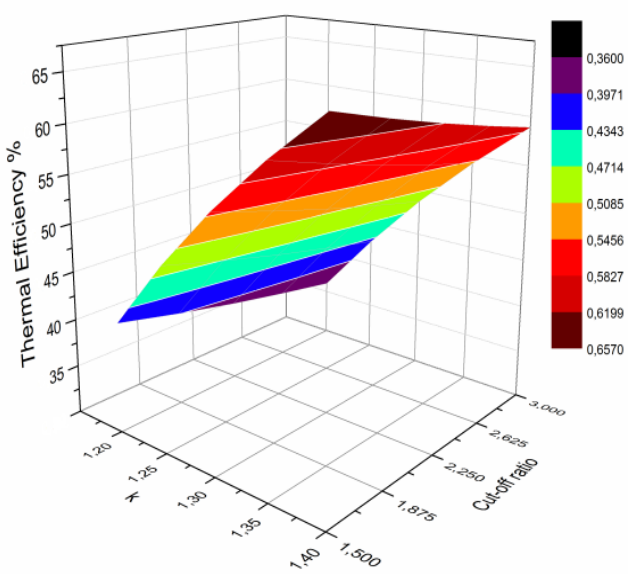

Fig. 6. The change in thermal efficiency according to different specific heats ratio and cut off ratio in cases where compression ratio is 18 constant

The calculation study showed that BTHE values can be obtained as up to $68 \%$. But this value is not realistic for actual applications since this study was evaluated with the formula of ideal diesel cycle. Idealization of actual diesel cyle includes many assumptions and thus there are tremendous differences between calculation datas and experimental datas. Hariram and Shangar published an article that researchs the effects of the compression ratio on combustion characteristics of a compression igntion engine [13]. The authors studied with three different compression ratios $(16: 1,17: 1$, and $18: 1)$. The authors reported that increasing CR resulted with higher BTHE values and thus lower brake specific fuel consumption. The author reported that increasing compression ratio from 16:1 to 18:1 improved BTHE value up to $13 \%$ at full load conditions which is coincidence with the calculation datas obtained in this study.

In another study V. Gnanamoorthi and G. Devaradjaneto found the maximum possible and optimum replacement of diesel fuel by ethanol and compare the performance of diesel engine fuel led with ethanol-diesel 
blend for various compression ratios $(17.5: 11,18.5: 1,19.5: 1)$ and study the effect of compression ratio and using the best emulsified technique to achieve acceptable range of efficiency up to E40.[14]

As it is shown in the experimental studies, increasing the compression ratio improves the efficiency of the engine. [25] In this study it was found a similar results that obtained in the previous studies.

\section{Conclusions}

- A theoretical study was evaluated with three parameters that effect the brake thermal efficiency of ideal diesel cyle.

- The parametrical study showed that increasing compression ratio significantly improves the brake thermal efficiency.

- The analyses revealed that, increasing ratio of specific heat further improves the brake thermal efficiency. But, increasing cut-off ratio resulted with lower brake thermal efficiency.

- Although, the calculation results were significantly different from the actual values, the trend of brake thermal efficiency with different parameters was compatible with actual processes.

- The calculations showed the effects of different operating parameters of the diesel engine based on ideal diesel cycle which can be used to optimize the operating conditions of a diesel engine.

\section{References}

[1] Demirbas A. "Biodiesel production from vegetable oils via catalytic and non-catalytic supercritical methanol transesterification methods." Progress in Energy and Combustion Science vol.31,pp.466-87,2005

[2] Amarnath, H.K., Prabhakaran, P., "A Study on the Thermal Performance and Emissions of a Variable Compression Ratio Diesel Engine Fuelled with Karanja Biodiesel and the Optimization of Parameters Based on Experimental Data. "International Journal of Green Energy, vol.9:8, pp.841-863,2012.

[3] Jindal S, Nandwana B.P., Rathore N.S., Vashistha V., "Experimental investigation of the effect of compression ratio and injection pressure in a direct injection diesel engine running on Jatropha methyl ester." Applied Thermal Engineering, vol.30,pp. 442-8, 2010.

[4] Mohanraj, T., Murugu Mohan Kumar, K., "Operating Characteristics Of A Variable Compression Ratio Engine Using Esterified Tamanu Oil." International Journal of Green Energy, vol.10:3,pp. 285-301, 2013.

[5] Muralidharan,K., Vasudevan, D., "Performance, emission and combustion characteristics of a variable compression ratio engine using methyl esters of waste cooking oil and diesel blends." Applied Energy, vol.88, pp. 3959-68, 2011.
[6] Hoeltgebaum, T., Simoni, R., Martins, D., "Reconfigurability of engines: A kinematic approach to variable compression ratio engine. "Mechanism and Machine Theory, vol.96, pp. 308-22, 2016.

[7] Serin H., M. Ozcanli, M.K. Gokce., G. Tuccar "Biodiesel Production From Tea Seed (Camellia Sinensis) Oil and its Blends With Diesel Fuel." International Journal of Green Energy, vol.10:4, pp.370-7., 2013.

[8] Yildizhan, S., Yasar, A., "Performance and Emission Characteristics of Diesel Engine Operating on Biodiesel and Biodiesel Blended with Methanol and Propanol." International Journal of Scientific and Technological Research, Vol 1, No.1, pp.270-8 2015.

[9] Ramadhas A.S., Muraleedharan C., and Jayaraj, S., "Performance and Emission Evaluation of a Diesel Engine Fueled with Methyl Esters of Rubber Seed Oil", Renewable Energy vol. 30,pp. 1789-1800,2005.

[10] Amarnath, H.K., and Prabhakaran P., "A Study on the Thermal Performance and Emissions of a Variable Compression Ratio Diesel Engine Fuelled with Karanja Biodiesel and the Optimization of Parameters Based on Experimental Data. "International Journal of Green Energy, vol.9:8, pp.841-863, 2012.

[11] Depnath, B.K., Sahoo, N., and Saha, U.K., "Thermodynamic analysis of a variable compression ratio diesel engine running with palm oil methyl ester. " Energy running with palm oil methyl ester. Energy Conversion and Management vol.65, pp.147-154. 2012.

[12] Al Dawody, M.F., and Bhatti, S.K., "Experimental and computational investigations for combustion, performance and emission parameters of a diesel engine fueled with soybean biodiesel-diesel blends. " Energy Procedia, biodiesel-diesel blends. vol.52,pp. 421-430,2014.

[13] Hariram, V., and Shangar, R.V., , "Influence of compression ratio on combustion and performance characteristics of direct injection compression ignition engine."Alexandria Engineering Journal, vol.54:4, pp.80781,2015 .

[14] V. Gnanamoorthi , G. Devaradjane "Effect of compression ratio on the performance, combustion and emission of DI diesel engine fueled with ethanol e Diesel blend." Journal of the Energy Institute,vol.88,pp.19-26,2015. 